\title{
How Can Safety Nets Contribute to Economic Growth?
}

\author{
Harold Alderman and Ruslan Yemtsov
}

\begin{abstract}
The paper provides an up-to date and selective review of the literature on how social safety nets contribute to growth. The evidence is carefully chosen to show how safety nets have the potential to overcome constraints on growth linked to market failures, and is organized into four distinct pathways: i) encouraging asset accumulation by changing incentives and by addressing imperfections in financial markets caused by constraints in obtaining credit, and from information asymmetries; overcoming such failures helps households to invest into their human capital or productive assets; ii) failures in insurance markets especially in low income setting; safety nets are assisting in managing risk both ex post and ex ante; iii) safety nets are overcoming failure to create assets and other local economy complementary factors to household-level investments; iv) safety nets are shown to relax political constraints on policy. Safety nets have a dual objective of directly alleviating poverty through transfers to the poor and of triggering higher growth for the poor. However, the trade-off between the dual objectives of equity and growth is not eliminated by the potential for productive safety nets; this remains critical for designing social policies. JEL codes: I38, O12, O15, H53, P46
\end{abstract}

Experience has taught that when they are well designed, safety nets ( $\mathrm{SN}$ ) can both redistribute the gains from growth and, at the same time, contribute to higher economic growth. The various channels by which SNs influence growth can be broadly classified into four pathways: i) safety nets enable households to make better investments in their future addressing some of the imperfections in markets caused by constraints in obtaining credit, inputs, and insurance, and from information asymmetries as well as by changing incentives to invest in human capital of children; ii) assisting in managing risk; safety nets help households manage risk both ex post and ex ante; iii) creation of community assets and iv) relaxing political constraints on policy. As such, growth can be achieved both by increasing the efficiency of private and public resource allocation in the

Harold Alderman (corresponding author) is a senior research fellow at the International Food Policy Research Institute. His email is h.alderman@cgiar.org. Ruslan Yemtsov is a lead economist at the World Bank. His email is ryemtsov@worldbank.org. The authors thank Xavier Gine for helpful suggestions on the draft.

THE WORLD BANK ECONOMIC REVIEW, VOL. 28, NO. 1, pp. 1-20

doi:10.1093/wber/lht011

Advance Access Publication June 3, 2013

(C) The Author 2013. Published by Oxford University Press on behalf of the International Bank for Reconstruction and Development / THE WORLD BANK. All rights reserved. For permissions, please e-mail: journals.permissions@oup.com 
short run and by encouraging additional investments in physical and human capital achieving returns that may be realized over decades.

The role of safety nets, defined here as non-contributory transfers generally targeted to the poor, in addressing inequality by raising the consumption of beneficiaries is well known and is largely a function of targeting efficiency as well as the impact of receipt of public transfers on private remittances and on labor supply. While there is ample heterogeneity in both coverage and generosity of safety nets globally (Grosh et al. 2008; Monchuk 2013), they can contribute substantially to the resources of the beneficiaries. For example, Mexico's oft studied cash transfer covered nearly a quarter of the population and provided an average increment of 20 percent over pre-transfer income to beneficiaries for an outlay of less than 0.5 percent of GNP in 2006 (Fiszbein and Schady). The potential to affect the lives of the poor then is widely documented; one decade into the $21^{\text {st }}$ century, between 0.75 and 1.0 billion people in low- and middle-income countries were receiving cash support from their governments (DFID, 2011). There is less known about the contribution of SN to growth. Evidence is, however, rapidly accumulating ${ }^{1}$ and as it goes directly to the motivation of governments to allocate funding, this paper presents examples of the various means by which transfers can promote economic growth organized around the four broad pathways mentioned above. The goal is to illustrate 'how' growth may be enhanced, rather than to measure 'how much' a given instrument has achieved overall or in a specific context. ${ }^{2}$ We focus particularly on cash transfers and public works designed primarily as a means to increase the earnings of low income individuals. These are by no means the only instruments that governments use to address equity while encouraging investments - direct price subsidies to schooling and health come to mind - but the main point of this are easily extrapolated to these additional components of a broader social policy strategy.

This evidence supports the view that transfers are not merely a means to reduce current poverty as measured by consumption but also a potential means to invest for future poverty reduction. ${ }^{3}$ Such investments, of course, have costs,

1. This paper covers a very different set of studies compared to a paper on a similar topic by Barrientos (2012); most of these additional studies have just been published or are forthcoming: this shows how dynamic this area of research is.

2. These are presented to illustrate prospective pathways; the paper is not a comprehensive review of any instruments such as offered by Fiszbein and Schady (2009) for conditional cash transfers. This paper also does not aim to discuss the administrative details of an effective program, such as addressing the efficiency of targeting.

3. The World Bank's recent Social Protection Strategy (World Bank, 2012) places safety nets as part of a system that also includes contributory social insurance and labor market programs that jointly address three goals, resilience, equity, and opportunity. See also, Alderman and Yemtsov (2012). There is not, however, a one to one mapping between these approaches and the goals; safety nets have the potential to contribute to realizing each of these, although most effectively as part of a system. In a like manner, Devereux and Sabates-Wheeler (2004) envision social protection as achieving four functions: protection, prevention, promotion and transformation. Relatively little is gained from compartmentalizing these or to assigning a single function to each social protection instrument. 
both in terms of the fiscal and deadweight costs of financing them and the potential for disincentives for labor force participation. But many of these costs accrue in the course of designing any targeted poverty program and are widely recognized. The assets created, by these transfer programs, however, are more recently acknowledged. Thus, safety nets fit appropriately within the larger category of pro-poor growth.

\section{Safety nets and Household Investments}

Transfers can offset missing credit markets. This is particularly helpful in regards to health and education as credit for such investments is rarely available but even in the case of agriculture where credit is, in principle, available SN may encourage the purchase of inputs. For example, following the introduction of the North American Free Trade Agreement (NAFTA) Mexico introduced a transfer program, Procampo, a targeted program designed to compensate farmers when subsidies were removed as part of trade reforms. Sadoulet, de Janvry, and Davis (2001) estimate that by relaxing liquidity constraints the transfers which averaged roughly 8 percent of the average household income of recipients led to a net increase of income that was nearly twice the value of the transfer. In a different context Ardington, Case, and Hosegood (2009) show that South African households in which a member receives an old age pension - in this particular example, one that is not financed from past contributions - use a share of the funds to finance migration and job search. ${ }^{4}$

Gertler, Martinez and Rubio-Codina (2012) confirm that poor households save out of SN transfers using experimental evidence, also from Mexico. This study based on the initial randomized evaluations of the conditional cash transfer program, Progresa (now called Oportunidades), found that the beneficiaries of the transfers invested 26 percent of the cash received, increasing the value of animals owned as well as participation in micro-enterprises. The propensity to save observed in this study was consistent with a wider literature on saving rates among poor households, but offers a particular insight in that it confronts the presumption that SN are mainly used for current consumption. Similarly, a recent paper based on a carefully designed survey to evaluate Ethiopia's Productive Safety Net Programme (PSNP), Berhane et al. (2011) find a persistent increase of livestock ownership as well as other assets among program participants.

Additionally, SNs are often designed to shift incentives, thus adding an additional spur to investments that goes beyond the relaxation of a credit constraint. This is motivated, in part, by the assumption that poor households under invest

4. In a related observation, Hoddinott et al. (2012) find that recipients of public works transfers in Ethiopia benefited more from other programs to enhance production than those who were only in the latter. 
relative to a social optimum. This might be the case if there are information asymmetries $^{5}$ or if there is a principal-agent problem in which the investor has a different incentive than the potential beneficiary as may be the case with girls who will leave the natal household (Das, Do, Ozler, 2005). ${ }^{6}$ This issue was raised in the first generation of conditional cash transfers (CCTs) (Fiszbein and Schady, 2009). But the objective in changing incentives may also reflect clear social externalities as with contagious illnesses; the recent generation of conditions for CCTs (at least at the pilot level) goes to a rather wide range of actions being incentivized including some health behaviors (preventing HIV/AIDS and sexually transmitted infections).

CCTs and school feeding programs are two of the best known transfer programs explicitly aimed at reducing the costs of investments to a household. ${ }^{7}$ There is evidence that even 'soft' conditions - actions that are advised as part of co-responsibility but which are not directly tracked to determine payments - can enhance the investments from these transfer programs relative to the impact of income in general. Still, firmer conditions to promote health seeking behaviors those that both monitor and enforce compliance - should, in principle, have an additional impact. This is not based on a patronizing view that the poor do not know how to spend their money wisely as occasionally depicted. Rather, this comes from a simple expectation that lowering a price of a service increases the use of that service more than does an equivalent income transfer. But, the record keeping that provides a timely flow of information from the service providers to the registers for payment requires a smoothly running system. As it is not easy to set up such a system, especially for health care since it occurs on a less regular schedule than does schooling, a key question when choosing between a conditional and an unconditional transfer (UCT), then, is whether these expected gains are worth the appreciable costs of monitoring.

While there have been a number of studies quantifying the share of increased income that poor households devote to investments for their children, in effect paralleling the question addressed by Gertler, Martinez and Rubio-Codina, ${ }^{8}$ a

5. The ability of fertilizer subsidies such as those in Malawi to increase profits for farmers is attributed to offsetting knowledge gaps as well as relaxing credit constraints. Recently, however, Duflo, Kremer, and Robinson (2011) have challenged these explanations for low use and offer an interpretation in terms of time inconsistency for budgeting and suggest a subsidy policy consistent with this interpretation. Additional evidence on input subsides is presented by Bardhan and Mookherjee (2011) who show that such subsides were highly profitable in West Bengal, India, although this study did not investigate market failures.

6. Bursztyn and Coffman (2012) interpret the preference for conditional transfers over larger unconditional ones observed in a sample of families in urban Brazil to information asymmetries in the context of different incentives between parents and their children. In this example, parents were well informed about returns to schooling but not able to adequately monitor the behavior of their children. The conditions served as a means to obtain additional information on school attendance.

7. See Alderman and Bundy (2012) for a review of school feeding programs from the perspective of safety nets.

8. See, for example, Behrman and Knowles (1999) on schooling. 
key question from the standpoint of $\mathrm{SN}$ design is how can a transfer program increase such investments. One issue that is common to both CCTs and UCTs is whether the recipient's gender matters. This was noted by Duflo (2003), who found that pensions received by women in South Africa had a significant impact on the nutritional status of their grandchildren, while this was not observed for male pensioners. The practical implications of this observation for child development, however, are less than often claimed since only 46 percent of pensioners either male or female-lived with their grandchildren and the impact was only observed if the woman's grandchild was a girl. On the other hand, this result does support the view that women and men have different patterns of investment. Akresh, de Walque, and Kazianga (2012a) also find small gender differences in expenditures in randomized trial of CCTs and UTCs in Burkina Faso but caution that there is not a clear case that father's under invest in children.

The amount of a transfer that is spent on human capital investments can also be enhanced by what is variously termed labeling (Kooreman, 2000) or social marketing. For example, Schady and Rosero (2008) found that household assigned randomly to an UCT, termed a social program, spent more on food than indicated in the expenditure patterns of similar households. It is, however, often difficult to distinguish the social marketing aspect of a transfer from the possibility that women have greater control of such labeled expenditures; Attanasio, Battistin and Mesnard (2012) note that both factors can contribute to the shift in the Engle functions for food they document in Colombia. Similarly, Macours, Schady and Vakis (2012) claim that one or both of these effects contributed to the outcomes in a cash transfer in Nicaragua. In particular, the role of social marketing likely accounts for the fact that impacts on child development did not fade out two years after the transfers ended. Similarly, the fact that households that were not eligible for a CCT in Indonesia also increased their health seeking behavior may also be due to the social marketing that accompanies such programs (World Bank, 2011).

CCTs go beyond labeling or social marketing to the degree that they strictly enforce compliance with conditions. Schady and Araujo (2008) report on a randomized transfer in Ecuador in which beneficiaries were told there was a schooling requirement but the condition was not strictly enforced. Those that believed there were co-responsibilities had higher enrollments than the other cash recipients. De Brauw and Hoddinott (2011) also investigated the additional impact of conditions over the transfer by looking at a subset of beneficiaries of Progresa that did not receive the forms necessary for monitoring program compliance. This group had lower enrollments than other CCT beneficiaries.

Both these studies verify that the differential impacts are not due to self or community selection. Moreover, their conclusions are bolstered by two recent randomized trials designed to test the impact of conditions over a similar unconditioned transfer. In a study of young women in Malawi Baird, McIntosh and Ozler (2011) found that both UCTs and CCTs reduced school dropout after two years but the reduction among UCT recipients was less than half of the reduced 
drop out when the students received CCTs. Akresh, de Walque, and Kazianga (2012b) also found that conditional transfers had a different impact on schooling than unconditioned transfers in a randomized trial in Burkina Faso. However, there results were nuanced in that there were no appreciable differences among core students, that is, among most primary school age children as among well higher ability children. In contrast, CCTs were more effective than UCTs in improving the enrollment of younger children and girls as well as children with lower ability. CCTs also performed better than UCTs in improving attendance and achievement scores.

To summarize this section, low income households use transfer programs to invest as well as to augment consumption. This investment can be enhanced through social marketing as well as by promoting a range of behaviors as a condition for eligibility. Initial studies on CCTs focused on changes in enrolment and health participation, with mixed evidence on the outcomes of this increased participation. More recent programs have broadened the activities to be encouraged - including participating prenatal and preschool programs as well as prevention of sexually transmitted diseases. Newer studies have also broadened the range of research regarding the heterogeneity of impacts and the manner in which programs can be designed. For example, evidence that the schooling response to a small CCT is not that much different than one to a larger CCT (Baird, McIntosh, and Ozler, 2011; Filmer and Schady, 2011) has practical implications as well as provides results that shed light on the role of social marketing. Nevertheless, both CCTs and UCTs are primarily aimed at stimulating demand for investments in health and education; their contribution to asset accumulation depends on the returns to those investments. The increase in demand does not always map to measurable impacts on either learning (Filmer and Schady, 2009) or nutritional status (Ruel and Alderman, 2013). In the latter case, Ruel and Alderman point to issues with the quality of service delivery as well heterogeneity of program beneficiaries; greater benefits have been noted for those who were more malnourished at the outset. ${ }^{9}$

\section{Safety Nets and Risk}

The ex ante role for the contribution of safety nets to growth is a fairly standard extension of the costs of income smoothing; risk averse farmers and entrepreneurs under-invest in a risky environment (Binswanger and Rosenzweig, 1993; Christiaensen, and Dercon, 2011; Elbers, Gunning, Kinsey 2007). The potential role for transfers to improve allocative efficiency is largely another aspect of missing or incomplete markets, in this case insurance as well as credit. However, while the potential for addressing this problem directly is attractive, market penetration of agricultural insurance in low income countries is still modest (Mahul

9. The bulk of evidence on CCTs comes from Latin America where undernutrition rates are far lower than in Africa or Asia. 
and Stutley, 2010). There are obstacles to insurance stemming from high costs and thus limited interest from private providers and low take-up on the part of farmers. Even when insurance is based on an easily observed rainfall index, thus reducing the well-known problems of moral hazard and asymmetric information that increase the cost of marketing insurance, low income households appear to be reluctant to purchase insurance (Gine, Townsend, and Vickery, 2008).

Mahul and Stutley (2010) point out that subsidies for insurance can enhance market development by making private provision more attractive and achieving scale economies. Subsidies can also assist in making insurance serve a role of safety nets. While Mahul and Stutley (2010) note many improvements in the provision of agricultural insurance in low income settings since Hazell's 1992 review found that payments far exceeded the premiums collected in many countries, they found that a few countries including India still have loss ratios greater than 100 percent. Given the substantial outlays for subsidies on insurance at least two questions are important. First, how well are subsidies targeted and, second, does insurance influence decisions taken by small farmers. Mahul and Stutley offer evidence on the former, finding that subsidies levels are often capped and occasional explicitly targeted to small and marginal farmers. ${ }^{10}$ Regarding the response of producers, a recent randomized trial in south India confirms that when provided with rainfall insurance farmers substitute production activities towards more profitable, but riskier, cash crops (Cole, Gine, and Vickery, 2011). Similarly, Cai et al (2010) observe that farmers in China raised more pigs when provided access to insurance. They also note that trust appears to be a limiting factor in take up, a conclusion also supported by field trials in India (Cole et al. 2013).

A safety net that households are able to view in advance as reliable can serve a similar function in allocative strategies as insurance does. However, any such program would likely also address credit constraints. Thus, it is a challenge to design a study that could isolate the specific pathway that contributes to any increased investments that might be observed. Bianchi and Bobba (2012) finesse this problem by comparing the effect of current transfers in Progresa on entrepreneurship with the effect of the amount of transfers expected for the future. They find that the latter has a larger impact on entrepreneurial activity implying that risk, more than liquidly constraints, had previously restricted occupational choices. ${ }^{11}$

It is somewhat easier to document the ex post role that a safety net can serve to protect household assets after an economic shock. While households employ a

10. This is a distinct approach from the use of index insurance or insurance principles to finance safety nets run at a national or regional level (Alderman and Haque, 2006). Under this approach the payout from insurance goes to an agency and is used to undertake public works or similar $\mathrm{SN}$ programs. This has been tried on a pilot basis but with the exception of a municipal drought program in Mexico, the approach has not been implemented as a pillar of national safety net programs.

11. Additionally, a general equilibrium effect of large and reliable safety nets might be a change of aggregate consumption stemming from a reduction in precautionary savings. 
range of strategies to smooth consumption in the wake of a setback, informal sharing arrangements tend to fall short for the poor in most circumstances as well as for the general population in times of covariate shocks (Bhattamishra and Barrett, 2010). For example, households cannot draw down liquid savings to meet all circumstances as savings cannot be negative; there are similar limits to credit access. Other strategies such as selling assets when prices are low or reducing investment in nutrition or schooling can contribute to poverty traps (Carter and Barrett, 2006). Some programs that have successfully protect investments have been designed explicitly as a response to shocks such as Indonesia's scholarship program designed in the wake of the 1997-1998 economic crisis (Cameron, 2009) or that country's efforts to protect nutrition (Giles and Satriawan, 2010). But other programs that are more broadly designed to address chronic poverty may also protect assets or investments. For example, de Janvry et al. (2006) observe that children in families that received Progresa transfers were less likely to drop out of school should an adult in their family become unemployed. Similarly, beneficiaries of Ethiopia's PSNP had fewer distress sales and had a statistically larger increase of assets over time (Devereux et al. 2005; Berhane et al. 2011).

While these examples are from poverty targeted programs, Sumarto, Suryahadi, and Pritchett (2007) indicate that a public employment program in Indonesia that was not sharply focused on the poor also served a significant insurance role for households from the middle of the distribution of expenditures or income. They argue that this program served as what they term a safety rope. While a safety net is intended to prevent consumption from falling below a minimum, in contrast, a safety rope is aimed at preventing a proportional loss of income or assets. A safety rope, then, can make a dynamic contribution to poverty prevention in times of crisis.

To recapitulate, poor households often trade off income gains against risk reduction and thus stay below the production possibilities of their assets. Moreover, they sometimes need to sell resources, or forego investments to smooth consumption fluctuations. Governments have attempted to address the absence of accessible insurance by directly providing or subsidizing insurance. The alternative means of insurance though the provision of safety nets has been shown to reduce disinvestment in the light of income shocks, but the contribution towards efficient investments by households depends on the perception of the authorities' ability to mount prompt and fair response after a shock. There is limited evidence that measures the degree to which efficiency gains are achieved in this manner.

\section{Safety Nets and Community Assets}

The most direct contributions to community assets come in the form of outputs from productive public works (Subbarao et al. 2013). In particular, many rural public works contribute to land management, which includes environmental and 
agricultural projects involving irrigation, afforestation, soil conservation, and watershed development. The example of PSNP in Ethiopia shows that over time local irrigation projects change the water available for agriculture (Subbarao et al., 2013). Less commonly, a public works project can also provide services that contribute to human resources. For example, the Jefes and Jefas program in Argentina supported child and elderly care, health program support, and community and school kitchens (Kostzer 2008). That program also permitted individuals to obtain training from outside providers as part of their participation, although the impact of this feature has apparently not yet been evaluated. However, while some public works programs seek to directly impart marketable job skills to their participants there is little evidence that this training goal has been achieved. Rwanda also allows participants in its public works to opt to have their wages deposited in a bank account. Their savings record can then be presented to micro-finance in the event that the participant seeks to set up an enterprise when the public works are completed. However, this also has not yet been evaluated. ${ }^{12}$

Labor intensive public works are not likely to be the most cost effective means to create the desired assets. ${ }^{13}$ Nevertheless, when non-wage inputs as well as engineering expertise are included in the planning process of a public works program this will enhance their asset creation impacts, but, within a fixed budget, will reduce the share of the program going to the direct beneficiaries as transfers. Whether this shift is justified in terms of the objectives of the transfer program is both an empirical and a policy question. Indeed, it is because public works trade off cost effectiveness in production against income support motives that they can be considered SNs as opposed to a more narrowly defined infrastructure investment. Public asset building in poor areas if properly done provides necessary complementary factor to household investment. Analysis of local economy effects from safety net transfers (as in Davies and Davey 2008 and Taylor et al., 2013 building on earlier work by Lewis and Thorbecke 1992) argues for positive effects on growth through the relaxation of demand constraints. Cash transfers often represent a significant share of household income and can be expected to help households overcome the obstacles that block their access to credit or cash. Households that were previously operating outside the cash economy become consumers with steady demand for goods and services. Transfer recipients become able to purchase daily necessities, assets, and

12. Linking transfers to savings encouragement - as is implicit in some alternative models of CCTs (Barrera-Osorio, 2011) - increases the potential to contribute to growth and blur the assignment of transfers to the category to consumption.

13. It is occasionally argued that in the absence of price distortions favoring capital, more projects would chose labor intensive works. There is limited evidence as to where and at what scale such projects are, given the real costs of managing a work force. We assume that in many circumstances labor intensive projects remain inside the production frontier and that in those circumstances clear trade-offs exist. Coady 2004 provides a detailed review. Adato and Haddad (2002) provide evidence that public works in South Africa have the same management tensions as private sector projects. 
livestock from local farmers and businesses. Most importantly, if safety nets are regular they have a stabilizing effect due to consumption smoothing in the face of seasonal and economic cycles. This, in turn, can increase productive and other income-generating investments in local economies.

While the short term effect on growth of such local stimuli is empirically demonstrated in multiple studies, the overall macroeconomic and longer term impact are less clear. First, the liquidity that is injected must come from somewhere as a tax with associated deadweight costs. In the long run the effects will be positive only if economy-wide permanently higher productivity growth is achieved. Otherwise, as noted by Barro (1976), the Ricardian equivalence effect may prevail (whereby households change their behavior in anticipation of future higher taxes to pay for government spending and as a result, offset the short run benefits of fiscal expansionary policies). However, Atkinson (1999) notes that the very existence of a welfare state is due to the imperfections of real world economies. In these second best situations the possibility that a safety net may stimulate a local economy is indeterminate; it may have positive or negative impact on economic performance depending on a host of factors.

Safety nets can overcome constraints on growth stemming from communitylevel factors, such as poor or absent local infrastructure or scarcity of local liquidity and trade; such effects are believed to be strongest in the case of localized "poverty traps" (Barrientos 2012). Evidence that safety net programs change income growth directly in the affected areas is available for China (Ravallion and Chen 2005) and Mexico (Angelucci and de Georgi 2009) and is being increasingly sought in Africa, East and South Asia. This is clearly one of the "growth poles" in research on safety nets. However, when the focus moves from micro- (household) to meso- (community) level it becomes clear that safety nets provide just an element of a broader development policy effort, and their specific contribution is hard to disentangle, especially when economy-wide effects are taken into consideration.

\section{Political Dimensions}

Safety nets facilitate the introduction of beneficial reforms by providing some compensation to offset the costs of these reforms to low income households. Additionally, since safety nets have an immediate impact on inequality and extreme poverty (valued in its own right) they contribute to social cohesion.

One illustration of the contribution that SNs make towards the acceptability of reforms can be found in the timing of the introduction of Procampo in Mexico. This program was introduced in 1994 as the North American Free Trade Agreement (NAFTA) was taking effect. The government recognized that small producers would be affected as domestic prices were reduced to reflect import parity of grain from the United States and Canada. Although based on area planted prior to the program (and thus regressive) Procampo also provided cash to farmers who had previously not had a market surplus and thus were not 
beneficiaries of the price supports that had been phased out. Transfers averaged $\$ 329$ per beneficiary in 1997 and contributed to the political acceptability of NAFTA as well as provided the multipliers via the cash used for inputs (Sadoulet, de Janvry and Davis, 2001).

Similarly, Indonesia was able to reduce fuel subsides by $\$ 10 \mathrm{~B}$ in 2005 without social unrest, in part, because a safety net program was introduced at the same time. Its approach included the inauguration of a targeted unconditional cash transfer program that utilized roughly a quarter of the savings in fuel subsidies. Additionally the government increased block grants to schools, health care and village improvement by an amount similar to the transfer program. Not only did the reform contribute to the government's overall financial position by providing $\$ 5 \mathrm{~B}$ to general revenues after both these new programs were funded, it contributed to economic efficiency by moving domestic prices for kerosene and gasoline closer to the cost of importing that Indonesia - formerly a net exporter - had been paying (Grosh et al. 2008).

Both NAFTA and Indonesia's fuel price reforms assisted in aligning domestic prices - in one case for producers and in the other for consumers -closer to the real resource costs and thus were clear contribution to efficient allocation of resources. Other safety net reforms can also be viewed as efficiency enhancing in that they can adapt the social transfer system in a manner that reduces the costs of achieving social ends. The introduction of Progresa served both roles. It facilitated the removal of food subsidies and their inherent distortions of price signals. Moreover, it consolidated various programs in diverse ministries - replacing them, rather than adding to them (Levy, 2006). This transformation of the administrative system is a second best welfare increasing reform - since it reduced the outlay required to meet an existing social goal - but by itself did not directly increase the assets or investments of low income households.

Safety nets may also contribute to growth on a national scale by reducing inequality and by increasing social cohesion (World Bank 2006). If, for example, there is an inequality trap via inequality of opportunity that reduces economic growth, then to the degree that SNs address asset accumulation through programs such as CCTs, fee waivers, or school feeding they can contribute to growth. A different pathway from equity to growth is also postulated, one in which inequality of outcomes influences the path of institutional development and sets up conditions which foster rent seeking. The theoretical underpinnings for this channel were initially formulated by Sala-i-Martin (1997) and later developed further by Mehlum, Moene, and Thorvick (2005) in a model in which positive growth effect is due to the deterrence of investment-reducing crime through safety nets.

Hard empirical evidence for this effect is difficult to come by, but this role for SNs is supported by the observation that safety nets often cultivate social reintegration in post conflict countries (such as Liberia and Sierra Leone), where public works have been offered to disaffected or potentially socially disruptive groups including former soldiers. Similarly, the public works program in El Salvador 
(PATI) directly targeted potentially delinquent youth and developed a scheme (combining transfers and training) that increased opportunity cost for participation in criminal activities (Subbarao et al. 2013).

There is less evidence on these potential avenues by which safety nets can contribute to growth via social capital for a variety of reasons. ${ }^{14}$ For example, it is difficult set up field trials on the impact of inequality on growth similar to those used to accumulate causal evidence of programs such as cash transfers. In addition, whether employing micro or macro level data it is a challenge to distinguish the effect of levels of assets from that of its distribution. Moreover, when looking at national data as in the claim of Boeri and Terrell (2002) that public assistance contributed to the speed of transition in Eastern Europe, programs that are generally contributory such as social insurance (unemployment insurance and pensions) are often aggregated with safety nets. ${ }^{15}$

However, it is also possible that SNs distract from cohesion rather than enhance it, depending in part on how the majority of the population reacts to any approach to redistribution and to targeting. ${ }^{16}$ While both the mechanics of targeting and deadweight costs of financing endogenous $\mathrm{SN}$ budgets are beyond the goals of this review, it is worth raising the issue of whether SNs raise political divisions. One perspective, illustrated by Gelbach and Pritchett (2000), is that support for SNs depends on providing a share of benefits to the middle class. Their inquiry is about sustainability; an early version of the cited paper asked if more for the poor meant less for the poor. However, the core question their model addresses can be paraphrased in terms of whether SNs are socially divisive. This is, of course, hard to test empirically. However, another perspective argues that society values fairness and thus better targeting is rewarded politically. This view has been tested in the context of Bolsa Escola, a transfer program in Brazil (now absorbed into a successor). de Janvry, Finan, and Sadoulet (2012) found that mayors with better performance in targeting had a higher likelihood of reelection. A final point on the possible link between political acceptance of safety nets and their contribution to economic growth returns to the issue of

14. Baez et al. (2012) use regression discontinuity to show that CCTs in Colombia increase voter participation. While this may be considered enhancing social capital, the authors also claim that since the participation favors the incumbents that promoted the program, it also risks encouraging patronage (although they do not provide a definition that distinguishes patronage from responsiveness, possibly the same action presented in a different light). See also, Manacorda, Miguel and Vigorito.(2011).

15. Ravallion (2003) reviews some evidence on aggregate growth being higher when inequality is lower, although the direct role of safety nets is seldom traced in this literature. To the degree that these results are generalizable they hold for various dimensions of pro-poor growth and not just safety nets. Thus, this aspect of Ravallion's review looks at the rate of growth and potential trade-offs; this is an additional theme that differs from the question of 'how' the contribution comes about - though other aspects of his review do address this as well.

16. Alesina and Giuliano (2010) present theoretical models of the preference for redistribution as well as data from the World Values Survey that document inter-country differences in this preference, with Eastern Europe and Latin America have higher than average preference. They also note that it is hard to separate redistribution and social insurance empirically. 
investments; regardless of the value society places on fairness, non-beneficiaries are more likely to support transfer programs if they are linked to prospects of graduation (the avoidance of dependency). Graduation, in turn, depends on the link of SNs to investments.

The political dimensions, then, covers two distinct pathways that have the potential to contribute to growth. First, whenever a SN makes a reform that removes economic distortions more likely there is a quantifiable economic benefit. The second category of gains are less easily measured; arguably social cohesion is a welfare improvement in itself but from the standpoint of economic gains, the benefits come from increased investments or more effective policy choices prompted by this social capital. While there is evidence that SNs may contribute to social cohesion in some circumstances (and be divisive in others) it is beyond the scope of this paper to review the literature on how such social capital augments economic growth.

\section{Measuring Net Impact}

This review has illustrated a range of impact on economic growth or on asset accumulation that can be attributed to safety nets. However, even if these examples are typical of the wider set of studies - and, as mentioned, the review is not intended as an exhaustive survey - there is still a major obstacle to quantifying the economic return to safety sets as an investment. The measurement of single dimension of the outcomes of a safety net program-say increased enrollment - as is often done in cost effectiveness studies biases the economic contribution of SNs downwards since it ignores the full range of outcomes.

Even if one could reasonably estimate the returns to the type of investments attributed to a safety net, transfer programs often have a dual objective of raising current consumption while simultaneously promoting investments. This makes it difficult to compare outcomes of a safety net with direct investments. The full social value of transfers does not easily aggregate with outputs in a benefit cost assessment. For one thing, such a summation requires a quantification of the weight society puts on consumption of the poor relative to that of the average citizen. Absent this calculation, a direct comparison of direct investments, say in education or health, with a SN does not put both categories of expenditures on the same metric. A cost benefit analysis or a cost effectiveness comparison within a sector generally assumes away the redistribution value of the transfer or ignores the benefits outside the sector being considered. Unfortunately, even though most societies place a value on redistribution, at least in their public statements, this value is not directly observable. However, excluding it from estimates of returns implicitly assumes this to have no value whatsoever.

There is another measurement problem that bedevils impact evaluation of $\mathrm{SN}$ : many assessments are designed to track the flow of services (such as enrollment or clinic visits) when the outcomes of interest for growth, such as learning or physical growth of children, is a measure of stock that is best assessed in the long term. 
While there are many possible explanations for increases in school attendance that do not translate into learning or in participation rates in child growth promotion that leaves malnutrition rates unchanged, one reason may be that the question is posed too soon (King and Behrman, 2009). Fortunately, there is increased interest in collecting data on panels of households or individuals and improved means for reducing attrition and for addressing it econometrically.

An additional gap in assessing the contribution of safety nets for growth as well as for equity is the challenge of assembling cost data and comparisons of modality of delivery. If, as implied above, one needs to consider the long run process of asset creation, then one needs both the costs of targeting and delivery as well as the continuing costs of the public investment to calculate a benefit cost ratio. This not only requires understanding delivery costs and assessing how to assign shares of fixed costs such as targeting to any cohort (Caldes, Cody, and Maluccio, 2006), it also requires understanding the marginal costs of, say, additional schooling induced by the increased investment in human capital.

Costs also include any labor disincentives. While these may be a substantial concern in programs that have an effective clawback that decreases transfers proportional to increases in income, such fine tuning is rare in low income settings. One example of the influence of targeting on labor allocation in a middle income country comes from a study by de Brauw et al. (2013). They note that even though Bolsa Familia had no disincentive effects on aggregate labor supply, it did prompt a reallocation from formal to informal activities, presumably as the latter were not a focus of means-testing. Whether this affects long term growth depends on the relative productivity in the sectors. Levy (2008) points out that the safety net system in Mexico has a class of benefits for formal sector employees and another set of informal sector employees. This sets up disincentives for entering the formal wage sector. Even beneficiaries' of Progresa-Oportunidades, which does not have a targeting mechanism linked to employment status and for which Levy claims the evidence does not show a direct impact on labor-leisure choice or labor participation, appear to be reluctant to change labor status as they are embedded in a matrix of programs which incentivize informal sector employment.

While these examples reflect the targeting mechanism, an additional potential cost to growth might come from increased demand for leisure. Empirical evidence, however, finds that reductions in overall adult labor supply attributable to SNs is minor (Skoufias and Di Maro, 2007; Alzua, Cruces and Ripani, 2012; Berhane et al. 2011, Grosh et al. 2008). Moreover, it is arguable whether similarly small reductions in child labor are a cost or a benefit stemming from the transfers. Likewise, Abdulai, Barrett and Hoddinott (2005) find that after controlling for the endogeneity of placement, there are no observed disincentives to agricultural labor or production attributable to food aid in Ethiopia.

Several carefully done studies from South Africa find an opposite effect among adults in participating households: workers in households receiving social grants look for work more intensively and extensively and find employment more 
successfully than do workers in comparably poor households that do not receive the grants (Samson and Williams, 2007). The availability of transfers may, however, shift intra-household labor choices. For example, South Africa's generous old age pension is associated with reduced work among prime age family members living with the recipients (Bertrand, Mullainathan, and Miller, 2003) offset by increased labor of household members who have migrated for job search (Ardington, Case, and Hosegood, 2009).

Social transfers, especially relatively generous unemployment compensations (formally classified as social insurance but de facto paid from general revenue) were a key factor of maintaining social peace during transition to market economy in Eastern Europe. They also had well documented effects on labor market behavior by recipients: increased duration of unemployment and reduced search efforts by recipients (Sanchez-Parramo, 2002; van Ours and Vodopivec, 2006) although the quality of job matching was not negatively affected (van Ours and Vodopivec, 2006). The level of support via unemployment insurance is, however, much larger relative to consumption than most other safety nets (up to 100 percent of formal sector wages over long period of time, measured by years in some cases) and this may explain the difference in observed labor impacts.

A different cost from shifting labor incentives has been noted for public works; since labor is shifted from other activities to the workfare, even if leisure is not affected, forgone earnings from these activities need to be subtracted from the wage benefits for public works (Ravallion, 1999). In a more general equilibrium context, however, to the degree than the foregone work was casual labor and that job specific skills and search costs are small, other workers will fill that labor demand providing a modest spillover to additional low income households. The various requirements necessary for qualifying for CCTs also affect labor or leisure or both with implicit costs of meeting these requirements often falling disproportionally on women.

Labor disincentives and reallocation are not the only responses that are grouped under disincentives in the literature. ${ }^{17}$ Transfers may also induce excess risk taking; however, as it is generally argued that risk aversion leads to poverty traps, not all shifting of risk to the state can be considered a social cost. A different form of distortion attributable to SNs may come when transfers are in terms of food. Is such circumstances the presence or absence of market distorting costs of the program follow from the rather context specific examples in the food aid literature (Barrett and Maxwell, 2005).

17. See the discussion in WFP (2006) and references in that paper. That review points out that there is a form of dependency that reflects needs - post disaster or life cycle related - as well as a cluster of disincentives that come under what the paper refers to as negative dependency. These cover a range of measurable economic concepts; however; dependency itself is often more a political category than a precise economic concept. 


\section{CONCLUSION}

Recent literature reveals a rich and fast-growing field of evidence on the mechanisms by which SNs affect growth. Still, even though there is clearly a positive contribution from safety nets programs to economic growth, the return on investment in safety nets cannot justify by itself the claim for limited public funds. It is the combination of their direct effect on poverty reduction along with their contribution to growth that jointly justifies investments in safety nets. That is, the growth argument in favor of safety nets is secondary to (and cannot fully displace) the equity argument. However, the social value is the sum of these two dimensions and thus the evidence on the contribution of safety nets to growth enhances the overall calculation of benefits.

However, there are tradeoffs on these two dimensions. For example, programs targeted to the elderly have (at best) only indirect productivity effects compared to allocating similar funds to children. Conversely, prioritizing funds towards programs linked to human capital investment or to public works has a recognizable investment potential but may exclude labor poor households or those that cannot take up opportunities for child investments. Thus, while consideration of the productive potential of SN reorients their role in the policy dialogue it does not eliminate the need to consider twin priorities of equity and efficiency.

\section{REFERENCES}

Abdulai, A., C. Barrett, and J. Hoddinott. 2005. "Does Food Aid Really Have Disincentive Effects? New Evidence from Sub-Saharan Africa.” World Development 33(10): 1689-1704.

Adato, M., and L. Haddad. 2002. "Targeting Poverty through Community-Based Public Works Programs: Experience from South Africa.” Journal of Development Studies 38 (3): 1-36.

Akresh, R., D. de Walque, and H. Kazianga. 2012a. “Alternative Cash Transfer Delivery Mechanisms: Impacts on Routine Preventative Health Clinic Visits in Burkina Faso.” World Bank Policy Research Working Paper \#5958. Washington, DC.

- 2012b. "Cash Transfers and Child Schooling: Evidence from a Randomized Evaluation of the Role of Conditionality." Unpublished manuscript.

Alderman, H., and D. Bundy. 2012. "School Feeding Programs and Development: Are We Framing the Question Correctly?” World Bank Research Observer 27(2): 204-21.

Alderman, H., and T. Haque. 2006. "Countercyclical Safety Nets for the Poor and Vulnerable." Food Policy 34(4): 372-83.

Alderman, H., and R. Yemtsov. 2012. "Productive Role of Safety Nets.” Background Paper for the World Bank 2012-2022 Social Protection and Labor Strategy, Social Protection \& Labor Discussion Paper No. 1203. Washington, DC.

Alesina, A., and P. Giuliano. 2010. "Preferences for Redistribution.” NBER Paper No. \#14825. National Bureau of Economic Research, Cambridge, MA.

Alzua, M. L., G. Cruces, and L. Ripani. 2012. "Welfare Programs and Labor Supply in Developing Countries - Experimental Evidence from Latin America.” Inter-American Development Bank working paper. Washington, DC.

Angelucci, M., and G. de Giorgi. 2009. "Indirect Effects of an Aid Program. How Do Cash Transfers Affect Ineligibles'Consumption.” American Economic Review 99(1): 486-508. 
Ardington, C., A. Case, and V. Hosegood, 2009. "Labor Supply Responses to Large Social Transfers: Longitudinal Evidence from South Africa.” American Economic Journal: Applied Economics 1(1): $22-48$

Atkinson, A. 1999. The Economic Consequences of Rolling Back the Welfare State. Cambridge, MA: MIT Press.

Attanasio, O., E. Battistin, and A. Mesnard. 2012. "Food and Cash Transfers: Evidence from Colombia." The Economic Journal 122(559): 92-124.

Baird, S., C. McIntosh, and B. Ozler. 2011. "Cash or Condition? Evidence from a Cash Transfer Experiment.” The Quarterly Journal of Economics 126(4): 1709-53.

Bardhan, P., and D. Mookherjee. 2011. "Subsidized Farm Input Programs and Agricultural Performance: A Farm-Level Analysis of West Bengal's Green Revolution, 1982-1995.” American Economic Journal: Applied Economics 3(4):186-214.

Baez, J., A. Camacho, E. Conover, and R. Zarate. 2012. "Conditional Cash Transfers, Political Participation, and Voting Behavior.” World Bank Policy Research Working Paper \#6215. Washington, DC.

Barrera-Osorio, F., M. Bertrand, L. Linden, and F. Perez-Calle. 2011. "Improving the Design of Conditional Transfer Programs: Evidence from a Randomized Education Experiment in Colombia." American Economic Journal: Applied Economics 3(2). 167-95.

Barrett, C., and D. Maxwell. 2005. Food Aid after 50 Years. Recasting its Role. New York: Routledge.

Barrientos, A. 2012. "Social Transfers and Growth: What Do We Know? What Do We Need to Find Out?" World Development 40(1): 11-20.

Barro, R. J. 1976. "Perceived Wealth in Bonds and Social Security and the Ricardian Equivalence Theorem: Reply to Feldstein and Buchanan.” Journal of Political Economy 84(2): 343-50.

Behrman, J., and J. Knowles. 1999. "Houseold Income and Child Schooling in Vietnam." World Bank Economic Review 13(2): 211-56.

Berhane, G., J. Hoddinott, N. Kumar, and A. Seyoum Taffesse. 2011. “The Impact of Ethiopia's Productive Safety Nets and Household Asset Building Programme: 2006-2010.” International Food Policy Research Institute, Washington, DC. Processed.

Bertrand M., S. Mullainathan, and D. Miller. 2003. "Public Policy and Extended Families: Evidence from Pensions in South Africa.” World Bank Economic Review 17(1): 27-50.

Bhattamishra, R., and C. Barrett. 2010. "Community-Based Risk Management Arrangements: A Review." World Development 38(7): 923-32.

Bianchi, M., and M. Bobba. 2012. "Liquidity, Risk, and Occupational Choices." The Review of Economic Studies. Advance online publication. doi. 10.1093/restud/rds031.

Binswanger, H., and M. Rosenzweig. 1993. "Wealth, Weather Risk, and the Composition and Profitability of Agricultural Investments.” Economic Journal 103(416):56-78.

Boeri, T., and K. Terrell. 2002. "Institutional Determinants of Labor Reallocation in Transition." Journal of Economic Perspectives 16(1): 51-76.

Bursztyn, L., and L. Coffman. 2012. “The Schooling Decision: Family Preferences, Intergenrational Conflict, and Moral Hazard in the Brazilian Favelas.” Journal of Political Economy 120(3): 359-97.

Cai, H., Y. Chen, H. Fang, and L-A. Zhou. 2009. "Microinsurance, Trust and Economic Development: Evidence from a Randomized Natural Field Experiment.” NBER Working Paper No. 15396. National Bureau of Economic Research, Cambridge, MA.

Caldes, N., D. Cody, and J. Maluccio. 2006. "The Cost of Poverty Alleviation Transfer Programs: A Comparative Analysis of Three Programs in Latin America.” World Development 34(5): 818-37.

Cameron, L. 2009. "Can a Public Scholarship Program Successfully Reduce School Drop-outs in a time of Economic Crisis? Evidence from Indonesia.” Economics of Education Review 28(3): 308-17.

Carter, M., and C. Barrett. 2006. "The Economics of Poverty Traps and Persistent Poverty: An Asset-Based Approach.” Journal of Development Studies 42(2): 783-99. 
Christiaensen, L., and S. Dercon. 2011. “Consumption Risk, Technology Adoption and Poverty Traps: Evidence from Ethiopia.” Journal of Development Economics 96(2): 159-73.

Coady, D. 2004. "Designing and Evaluating Safety Nets: Theory, Evidence, and Policy Conclusions." FCND Discussion Paper 172. International Food Policy Research Institute, Washington DC.

Cole, S., X. Giné, J. Tobacman, P. Topalova, R. Townsend, and J. Vickery. 2013. "Barriers to Household Risk Management: Evidence from India.” American Economic Journal: Applied Economics 5(1): 104-35.

Cole, S., X. Giné, and J. Vickery. 2011. "How Does Risk Management Influence Production Decisions? Evidence from a Field Experiment.” World Bank, Washington, DC. Processed.

Das, J., Q-T. Do, and B. Özler. 2005. "Reassessing Conditional Cash Transfer Programs.” World Bank Research Observer 20(1): 57-80.

Davies, S., and J. Davey. 2008. “A Regional Multiplier Approach to Estimating the Impact of Cash Transfers on the Market: The Case of Cash Transfers in Rural Malawi." Development Policy Review 96 (1): 91-111.

De Brauw, A., and J. Hoddinott. 2011. "Must Conditional Cash Transfer Programs Be Conditioned to Be Effective? The Impact of Conditioning Transfers on School Enrollment in Mexico." Journal of Development Economics 96(2): 359-70.

De Brauw, A., D. O. Gilligan, J. Hoddinott, and S. Roy. 2013. "Bolsa Família and Household Labor Supply.” International Food Policy Research Institute, Washington, DC. Processed.

De Janvry, A., F. Finan, E. Sadoulet, and R. Vakis. 2006. "Can Conditional Cash Transfer Programs Serve as Safety Nets in Keeping Children at School and from Working when Exposed to Shocks?” Journal of Development Economics 79: 349-73.

De Janvry, A., F. Finan, and E. Sadoulet. 2012. "Local Electoral Incentives and Decentralized Program Performance." Review of Economics and Statistics 94(3): 672-85.

Devereux, S., J. Marshall, J. MacAskill, and L. Pelham. 2005. "Making Cash Count: Lessons from Cash Transfer Schemes in East and Southern Africa for Supporting the Most Vulnerable Children and Households." Save the Children UK, HelpAge International and Institute of Development Studies, London and Sussex, UK.

Devereux, S., and R. Sabates-Wheeler. 2004. “Transformative Social Protection.” IDS Working Paper 232. Institue of Development Studies, Brighton, UK.

DFID. 2011. Cash transfer evidence paper. Department for International Development (DFID) Policy Division, London.

Duflo, E. 2003. "Grandmothers and Granddaughters: Old-Age Pensions and Intra-household Allocation in South Africa.” World Bank Economic Review 17(1): 1-25.

Duflo, E., M. Kremer, and J. Robinson. 2011. "Nudging Farmers to Use Fertilizer: Theory and Experimental Evidence from Kenya.” American Economic Review 101(6): 2350-90.

Elbers, C., J. Willem Gunning, and B. Kinsey. 2007. "Growth and Risk: Methodology and Micro Evidence.” World Bank Economic Review 21: 1-20.

Filmer, D., and N. Schady. 2011. "Does More Cash in Conditional Cash Transfer Programs Always Lead to Larger Impacts on School Attendance?" Journal of Development Economics 96(1):150-57.

- 2009. "School Enrolment, Selection, and Test Scores.” World Bank Policy Research Working Paper \#4998. World Bank, Washington, DC.

Fiszbein, A., and N. Schady. 2009. "Conditional Cash Transfers for Attacking Present and Future Poverty.” Policy Research Report. World Bank, Washington, DC.

Gelbach, J., and L. Pritchett. 2000. "Indicator Targeting in a Political Economy: Leakier Can Be Better." Policy Reform 4: 113-45.

Gertler, P., S. Martinez, and M. Rubio-Codina. 2012. "Investing Cash Transfers to Raise Long-Term Living Standards.” American Economic Journal: Applied Economics 4 (1): 164-92. 
Giles, J., and E. Satriawan. 2010. "Protecting Child Nutritional Status in The Aftermath of a Financial Crisis: Evidence from Indonesia.” World Bank Policy Research Working Paper \#5471. World Bank, Washington, DC.

Gine, X., R. Townsend, and J. Vickery. 2008. "Patterns of Rainfall Insurance Participation in Rural India." World Bank Economic Review 22: 539-66.

Grosh, M., C. Del Ninno, E. Tesliuc, and A. Ouerghi. 2008. For Protection and Promotion: The Design and Implementation of Effective Safety Nets. Washington DC: World Bank.

Hazell, P. 1992. “The Appropriate Role of Agricultural Insurance in Developing Countries.” Journal of International Development 4(6):567-81.

Hoddinott, J., G. Berhane, D. Gilligan, N. Kumar, and A. Seyoum Taffesse. 2012. "The Impact of Ethiopia's Productive Safety Net Programme and Related Transfers on Agricultural Productivity." Journal of African Economies 21(5): 761-86.

King, E., and J. Behrman. 2009. "Timing and Duration of Exposure in Evaluations of Social Programs." World Bank Research Observer 24(1): 55-82.

Kooreman, P. 2000. “The Labeling Effect of a Child Benefit System.” American Economic Review 90(3): $571-83$.

Kostzer, D. 2008. "Argentina-A Case Study on the Plan Jefes y Jefas de Hogar Desocupados, or the Employment Road to Economic Recovery.” Working Paper 534. The Levy Economics Institute, Annandale-on-Hudson, NY.

Levy, S. 2006. Progress against Poverty. Washington DC: Brookings Institute.

- 2008. Good Intentions, Bad Outcomes: Social Policy, Informality, and Economic Growth in Mexico. Washington DC: Brookings Institute.

Lewis, B. D., and E. Thorbecke. 1992. "District-Level Economic Linkages in Kenya: Evidence Based on a Small Regional Social Accounting Matrix.” World Development 20(6): 881-97.

Macours, K., N. Schady, and R. Vakis. 2012. "Cash Transfers, Behavioral Changes, and cognitive development in early childhood: Evidence from a Randomized Experiment." American Economic Journal: Applied Economics 4(2): 247-73.

Mahul, O., and C. Stutley. 2010. Government Support to Agricultural Insurance: Challenges and Options for Developing Countries. Washington DC: World Bank.

Manacorda, M., E. Miguel, and A. Vigorito. 2011. "Government Transfers and Political Support." American Economic Journal: Applied Economics 3(3):1-28.

Mehlum, H., K. Moene, and R. Torvik. 2005. "Crime Induced Poverty Traps.” Journal of Development Economics 77: 325-40.

Monchuk, V. 2013. "Social Safety Nets in Africa - A Review of Experience in 20 Countries." World Bank. Forthcoming.

Ravallion, M. 1999. “Appraising Workfare.” World Bank Research Observer 14(1): 31-48. . 2003. "Targeted Transfers in Poor Countries: Revisiting The Trade-Offs and Policy Options.” World Bank Policy Research Working Paper \#3048. World Bank, Washington, DC.

Ravallion, M., and S. Chen. 2005. "Hidden Impact: Household Saving in Response to a Poor-Area Development Project.” Journal of Public Economics 89(11-12): 2183-204.

Ruel, M., and H. Alderman. 2013. "Nutrition-Sensitive Interventions and Programs: How Can They Help Accelerate Progress in Improving Maternal and Child Nutrition?" The Lancet. Forthcoming.

Sadoulet, E., A. de Janvry, and B. Davis. 2001. "Cash Transfer Programs with Income Multipliers: PROCAMPO in Mexico.” World Development 29 (6): 1043-56.

Sala-I-Martin, X. 1997. “Transfers, Social Safety Nets, and Economic Growth.” International Monetary Fund Staff Papers 44 (1): 81 - 102.

Sánchez-Páramo, C. 2002. "Unemployment, Skills, and Incentives: An Overview of the Safety Net System in the Slovak Republic.” Policy Research Working Paper Series 2753. The World Bank, Washington, DC. 
Samson, M., and M. Williams. 2007. "A Review of Employment, Growth and Development Impacts of South Africa's Social Transfers.” EPRI Working Paper No. 41. Economic Policy Research Institute, Cape Town, South Africa.

Schady, N., and M. Caridad Araujo. 2008. "Cash Transfers, Conditions, and School Enrollment in Ecuador." Economía 8: 43-70.

Schady, N., and J. Rosero. 2008. "Are Cash Transfers Made to Women Spent Like Other Sources of Income?” Economics Letters 101(3): 246-48.

Skoufias, E., and V. Di Maro. 2008. "Conditional Cash Transfers, Adult Work Incentives and Poverty.” Journal of Development Studies 44(7): 935-60.

Skoufias, E., M. Unar, and T. Gonzalez-Cossio. 2008. "The Impacts of Cash and In-Kind Transfers on Consumption and Labor Supply: Experimental Evidence from Rural Mexico.” Policy Research Working Paper Series 4778. The World Bank, Washington, DC.

Subbaro, K., C. del Ninno, C. Andrews, and C. Rodriguez-Alas. 2013. Public Works as a Safety Net. Design, Evidence and Implementation. Washington, DC: World Bank.

Sumarto, S., A. Suryahadi, and L. Pritchett. 2007. "Safety Nets or Safety Ropes? Dynamic Benefit Incidence of Two Crisis Programs in Indonesia.” World Development 31 (7): 1257-77.

Taylor, E., M. Filipski, K. Thome, J. Kagin, and B. Davies. 2013. "Agricultural Spillover Effects of Cash Transfers: What Does LEWIE Have to Say?” American Journal of Agricultural Economics. Forthcoming.

Van Ours, J., and M. Vodopivec, 2006. "Duration of Unemployment Benefits And Quality of Post-Unemployment Jobs: Evidence From A Natural Experiment.” Policy Research Working Paper Series 4031. The World Bank, Washington, DC.

World Bank. 2012. Resilience, Equity and Opportunity. Social Protection and Labor strategy 2012-2022. Washington, DC: World Bank.

—. 2011. "Program Keluarga Harapan. Impact Evaluation Report of Indonesia's Household Conditional Cash Transfer Program.” Unpublished paper.

—. 2006. "Equity and Development." World Development Report Washington DC: Oxford University Press.

World Food Program. 2005. "Food Aid and Dependency: Implications for Emergency Food Security Assessments.” Rome, Italy. 